\title{
COMPETIÇÃO DE ADUBOS FOSFATADOS NO ALGODOEIRO, EM ENSAIO DE LONGA DURAÇÃO (')
}

\author{
NELSON MACHADO DA SILVA (2), LUIZ HENRIQUE CARVALHO $(2,4)$, \\ EDERALDO JOSÉ CHIAVEGATO $(2,4)$, NELSON PAULIERI SABINO $(3,4)$ \\ E JULIO ISAO KONDO $(3,4)$
}

\begin{abstract}
RESUMO
Após quatro anos de aplicaçōes sucessivas de misturas de adubos contendo $P$ ou $P$ mais $S$, em ensaio permanente com o algodoeiro, fez-se rotaçāo com cultivo de mucuna-preta na entressafra do quarto para o quinto ano, seguida de calagem visando à adequada correçāo da acidez do solo. No qüinqüênio 1978-1983, cultivou-se a variedade IAC 18 de algodoeiro, mantendo-se a mesma adubaçāo da primeira fase, que, através de combinações de produtos comerciais, como sulfato de amônio, Nitrocálcio, superfosfato triplo, superfosfato simples e cloreto de potássio, forneceu anualmente às plantas $\mathrm{N}$ e $\mathrm{K}$ em doses constantes e $\mathrm{P}$ e $\mathrm{S}$ em doses variáveis. Sintomas de deficiência de enxofre, representados especialmente pelo "verde-limão" das folhas de ponteiro, tornaram-se evidentes a partir do quinto ano agricola (primeiro da segunda fase), coincidindo com tendência para aumento de produtividade do algodoeiro. Entretanto, só após a correção da acidez do solo ( $\mathrm{pH}$ em $\mathrm{H}_{2} \mathrm{O}$ ao redor de 6,2$)$, é que a produtividade das plantas se estabilizou em nivel alto, e as diferenças a favor das misturas contendo superfosfato simples tornaram-se estatisticamente significativas. $\mathrm{Na}$ segunda fase, as doses de 50 e $100 \mathrm{~kg} / \mathrm{ha}$ de $\mathrm{P}_{2} \mathrm{O}_{5}$ proporcionaram
\end{abstract}

(1) Trabalho apresentado na XVII Reunião Brasileira de Fertilidade do Solo, Londrina (PR), em julho de 1986. Recebido para publicação em 26 de agosto de 1986.

(2) Seção de Algodão, Instituto Agronômico (IAC), Caixa Postal 28, 13001 Campinas (SP).

(3) Seção de Tecnologia de Fibras, IAC.

(4) Com bolsa de pesquisa do CNPq. 
acréscimos no volume de produçāo, respectivamente de 37 e $40 \%$, quando se usou superfosfato triplo na adubação, e de 55 a $67 \%$ no caso do superfosfato simples. Em termos de lucro, o superfosfato simples proporcionou acréscimos sobre o triplo da ordem de 55 a $82 \%$, em função da dose de $\mathrm{P}_{2} \mathrm{O}_{5}$ usada. Peso de capulho e comprimento de fibra também foram significativamente beneficiados pelo superfosfato simples, enquanto o fornecimento suplementar de enxofre, $120 \mathrm{~kg} / \mathrm{ha}$ de $\mathrm{S}$, não alterou as caracteristicas gerais do algodoeiro adubado com a dose básica de $60 \mathrm{~kg} / \mathrm{ha}$ de S. É proposto que se reavalie a necessidade de incorporar enxofre nas formulaçōes comerciais de adubos, diante dos resultados obtidos.

Termos de indexação: algodāo; capulho, peso; fibra, comprimento, e superfostatos simples e triplo.

\section{INTRODUÇÃO}

Admite-se que a disponibilidade de enxofre em solos ácidos seja baixa em função da fraca atividade microbiana na decomposição da matéria orgânica fonte natural do nutriente - e da alta taxa de adsorção pelos colóides minerais (WUTKE, 1972, e MENGEL \& KIRKBY, 1978). A elevação do pH do solo, com a prática da calagem, deve concorrer para liberar enxofre da matéria orgânica $e$ para diminuir a adsorção do ânion sulfato pela fração mineral (WUTKE, 1972). Experimentalmente, no entanto, não se tem demonstrado que tais fatores, ligados à disponibilidade desse nutriente, possam afetar o crescimento das plantas (HINKLE \& BROWN, 1968).

Misturas de adubos contendo superfosfato triplo têm sido comparadas a misturas com superfosfato simples associado ou não a sulfato de amônio, em ensaio de longa duração conduzido com o algodoeiro em latossolo roxo ácido. Résultados preliminares de SILVA et al. (1981) indicaram nítida tendência para maior resposta do algodoeiro às misturas de adubos contendo enxofre, embora os sintomas de deficiência do nutriente não se tenham evidenciado nos primeiros anos. A partir do quarto ano de estudo, promoveu-se uma efetiva recuperação da gleba experimental com o uso de calcário dolomítico e cultivo de leguminosa em rotação. Resultados de produção e de outras características do algodoeiro, nos cinco anos subseqüentes, são apresentados e discutidos a seguir.

\section{MATERIAL E MÉTODOS}

No encerramento da primeira fase do estudo de competição de adubos fosfatados, procedeu-se ao cultivo de mucuna-preta durante a entressafra do quarto para o quinto ano agricola. A leguminosa foi semeada em março, na primeira colheita de algodão, e incorporada em agosto de 1978. A partir desse ano, 
- ensaio foi semeado com a variedade IAC 18 de algodoeiro, mantendo-se a mesma adubação da primeira fase, conforme detalhes expostos em SILVA et al. (1981). Resumidamente, utilizaram-se as doses de $52,2 \mathrm{~kg} / \mathrm{ha}$ de $\mathrm{Ne} 75 \mathrm{~kg} / \mathrm{ha}$ de $\mathrm{K}_{2} \mathrm{O}_{4}$ para todas as parcelas, e doses variáveis de $\mathrm{P}_{2} \mathrm{O}_{5}$ e S, conforme os seguintes tratamentos e respectivos símbolos: testemunha (t), sem fósforo e sem enxofre; $50 \mathrm{~kg} / \mathrm{ha}$ de $\mathrm{P}_{2} \mathrm{O}_{5}(\mathbf{p}) ; 100 \mathrm{~kg} / \mathrm{ha}$ de $\mathrm{P}_{2} \mathrm{O}_{5}(2 \mathrm{p}) ; 50 \mathrm{~kg} / \mathrm{ha}$ de $\mathrm{P}_{2} \mathrm{O}_{5}$ e $30 \mathrm{~kg} / \mathrm{ha}$ de $\mathrm{S}(\mathbf{p}+\mathbf{s}) ; 100 \mathrm{~kg} / \mathrm{ha}$ de $\mathrm{P}_{2} \mathrm{O}_{5}$ e $60 \mathrm{~kg} / \mathrm{ha}$ de $\mathrm{S}(2 \mathrm{p}+2 \mathrm{~s})$ e $100 \mathrm{~kg} / \mathrm{ha}$ de $\mathrm{P}_{2} \mathrm{O}_{5}$ e $120 \mathrm{~kg} / \mathrm{ha}$ de $S(2 p+4 \mathbf{s})$. A mistura de adubos usada na semeadura, no primeiro tratamento, foi preparada com Nitrocálcio ( $8 \mathrm{~kg} / \mathrm{ha}$ de $\mathrm{N})$ e cloreto de potássio; no segundo e terceiro traramentos, acrescentou-se superfosfato triplo e, nos demais, superfosfato simples. Efetuou-se a cobertura nitrogenada $(44,2 \mathrm{~kg} / \mathrm{ha}$ de N) com Nitrocálcio, exceto no último tratamento, com sulfato de amônio. Para distribuição dos tratamentos no campo experimental, adotou-se o quadrado latino.

Em setembro de 1979, ou seja, no início do sexto ano agricola, realizouse uma terceira aplicação de calcário dolomítico $(3,5 \mathrm{t} / \mathrm{ha})$, dando continuidade ao plano de correçăo iniciado na primeira fase. Amostras de solo coletadas a cada ano permitiram acompanhamento da correção da acidez do solo. Originalmente, a gleba de latossolo roxo mostrou-se ácida ( $\mathrm{pH} \mathrm{em} \mathrm{H}_{2} \mathrm{O}$ por volta de 5,0 ) e pobre em matéria orgânica (cerca de $2,0 \%$ de M.O.).

Efetuou-se a colheita do algodão nas duas linhas úteis de cada canteiro, em duas etapas, sendo a relação primeira colheita/colheita total, dada em porcentagem, usada para indicar a precocidade das plantas. Na primeira colheita, retirou-se uma amostra de vinte capulhos por parcela experimental para estudos de laboratório. Os pesos de capulho e de cem sementes correspondem a determinações médias, expressas em gramas. A porcentagem de fibra, obtida após o beneficiamento da amostra, representa o valor médio da porcentagem ponderal da fibra. O comprimento da fibra algodoeira, dado em milimetro, corresponde ao valor médio do comprimento. "2,5\%", fornecido pelo Fibrógrafo, enquanto a uniformidade, expressa em porcentagem, foi calculada pela relação entre os comprimentos " $50 \%$ " e $2,5 \%$ ". O indice Micronaire, determinado em aparelho de mesmo nome, representa o complexo finura + maturidade da fibra.

São apresentados e discutidos resultados de análises de variâncias efetuadas em dados anuais de produção, e de análises conjuntas dos resultados correspondentes ao segundo período (do quinto ao nono ano), para produção e demais características. No caso especial da produção, fez-se uma análise comparativa da eficiência do uso dos superfosfatos, através de um retrospecto até aos primeiros anos do estudo. Procedeu-se, ainda, a uma análise econômica simplificada da produção, com dados dos últimos cinco anos. Calcularam-se os acréscimos de produção em relação à testemunha (sem $\mathrm{P}$ e sem $\mathrm{S}$ ), acumulados durante esses anos, extraindo-se deles os custos totais (em termos de produto) dos fertilizantes fornecedores de $\mathrm{P}$ e de $\mathrm{N}$ (em cobertura), assim como os custos da colheita dos acréscimos de produção. Não se consideraram as despesas com 
transporte dos adubos, por dependerem da distância dos centros de distribuição às diversas regiōes produtoras, e essa ser de dificil determinação, nem os demais gastos, comuns a todos os tratamentos. Adotaram-se indices financeiros relativos a 1986, coletados junto ao Instituto de Economia Agricola, da Secretaria da Agricultura e Abastecimento do Estado de São Paulo, a saber: Cz $\$ 1.883,00 /$ tonelada de superfosfato simples; Cz $\$ 3.439,00 /$ tonelada de superfosfato triplo; Cz $\$ 1.929,00 /$ tonelada de sulfato de amônio; Cz $\$ 1.660,00 /$ tonelada de Nitrocálcio; $\mathrm{Cz} \$ 76,00 /$ arroba de algodão em caroço e $\mathrm{Cz} \$ 13,00$ para a colheita de uma arroba de algodão.

Foram descritos, ainda, sintomas de deficiência de enxofre e apresentadas fotos ilustrativas dessa ocorrência. Resultados de análises química de solo e de folha deverão ser tratados detalhadamente em outro trabalho.

\section{RESULTADOS}

\subsection{Efeitos sobre a produção e sobre o aspecto do algodoeiro}

O quadro 1 apresenta os dados médios de produção obtidos anualmente por tratamento, do quinto ao nono ano de estudo com a variedade IAC 18, e os resultados das respectivas análises estatísticas.

QUADRO 1. Resultados médios de algodão em caroço obtidos do quinto ao nono ano de estudo de competição de adubos fosfatados, em ensaio permanente conduzido com a variedade IAC 18, em latossolo roxo de baixa fertilidade, no periodo 1978/79-1982/83, em Guaira, SP

Tratamento

\begin{tabular}{|c|c|c|c|c|c|c|c|c|}
\hline \multirow{3}{*}{ Simbolo } & \multirow{2}{*}{\multicolumn{2}{|c|}{ Doses }} & \multicolumn{6}{|c|}{ Produção } \\
\hline & & & \multirow{2}{*}{$.1978 / 79$} & \multirow{2}{*}{$1979 / 80$} & \multirow{2}{*}{$1980 / 81$} & \multirow{2}{*}{1981782} & \multirow{2}{*}{$1982 / 83$} & \multirow{2}{*}{ Médie } \\
\hline & $\mathrm{P}_{2} \mathrm{O}_{5}$ & $S$ & & & & & & \\
\hline
\end{tabular}

\begin{tabular}{|c|c|c|c|c|c|c|c|c|}
\hline \multicolumn{3}{|c|}{$\mathrm{kg} / \mathrm{ha}$} & \multicolumn{6}{|c|}{$\mathrm{kg} / 10 \mathrm{~m}^{2}$} \\
\hline$t$ & 0 & 0 & $1,120 \mathrm{c}\left({ }^{1}\right)$ & $2,488 c$ & $2,048 d$ & $1,575 \mathrm{e}$ & $1,755 \mathrm{c}$ & $1,797 \mathrm{c}$ \\
\hline $\mathbf{p}$ & 50 & 0 & $2,182 b$ & $3,465 b$ & $2,610 c$ & $1,808 d$ & $2,232 b$ & $2,459 b$ \\
\hline $2 p$ & 100 & 0 & $2,278 a b$ & $3,410 b$ & $2,653 b c$ & $1,893 \mathrm{~cd}$ & $2,378 a b$ & $2,523 b$ \\
\hline$p+s$ & 50 & 30 & $2,292 a b$ & $3,913 a$ & $2,938 b$ & $2,290 b c$ & $2,628 \mathrm{a}$ & $2,792 a$ \\
\hline $2 p+2 s$ & 100 & 60 & $2,580 a$ & $3,955 a$ & $3,427 a$ & $2,487 a b$ & $2,598 \mathrm{ab}$ & $3,009 a$ \\
\hline $2 p+4 s$ & 100 & 120 & $2,157 \mathrm{~b}$ & $4,077 a$ & $3,373 a$ & $2,638 a$ & $2,358 a b$ & $2,921 a$ \\
\hline Média & & & 2,101 & 3,535 & 2,842 & 2,115 & 2,325 & 2,584 \\
\hline "F" - Trat & & & $24,29^{* *}$ & $41,67^{\star \star}$ & $26,38^{* *}$ & $32,70^{\star *}$ & $10,60^{* *}$ & $24,77^{* *}$ \\
\hline CV\% & & & 11,9 & 6,2 & 8,7 & 8,5 & 10,3 & 8,9 \\
\hline
\end{tabular}

(1) Teste de Duncan a $5 \%$ de probabilidade. Comparação entre médias de tratamentos, dentro de ano. 
O efeito devido a tratamentos foi significativo em todos os anos, conforme indicam os valores de " $F$ " obtidos em ensaios de boa precisão, pois os coeficientes de variação das análises estiveram entre 6,2 e 11,9\%. Em todos os anos, a testemunha $(\mathrm{t})$ apresentou a menor produção média, sendo superada estatisticamente pelos tratamentos que receberam a dose de $50 \mathrm{~kg} / \mathrm{ha}$ de $\mathrm{P}_{2} \mathrm{O}_{5}$, quer sob a forma de superfosfato triplo $(\mathbf{p})$, quer simples $(\mathbf{p}+\mathbf{s})$. Por sua vez, a dose de $100 \mathrm{~kg} / \mathrm{ha}$ de $\mathrm{P}_{2} \mathrm{O}_{5}$ só diferiu da dose intermediária quando fornecida por superfosfato simples $(2 p+2 s)$, em 1980/81. A adiçáo suplementar de enxofre, representada pela cobertura com sulfato de amônio em parcelas adubadas com a dose máxima de superfosfato simples, nada acrescentou à produtividade média do algodoeiro; aliás, concorreu para diminuí-la em 1978/79 e, de certa forma, em 1982/83.

$\mathrm{Na}$ análise conjunta (última coluna do quadro 1), identificaram-se três grupos estatisticamente distintos: o da testemunha absoluta ( $t$ ), com a menor produção; o grupo dos tratamentos que receberam superfosfato triplo com acréscimos sobre a produção da testemunha entre 37 e $40 \%$, e o grupo das misturas contendo superfosfato simples ou superfosfato simples mais sulfato de amônio, com acréscimos de 55 a $67 \%$.

No período anterior, segundo SILVA et al. (1981), os aumentos porcentuais de produção observados foram até maiores, porém nem sempre significativos: ocorre que a produtividade das plantas havia sido baixa, a julgar pela média da testemunha, $0,648 \mathrm{~kg} / 10 \mathrm{~m}^{2}$. Além disso, a precisão estatística dos ensaios foi menor, tendo os valores do coeficiente de variação oscilado entre 11,4 e 16,9\%.

Com o cultivo de leguminosa após o quarto ano e com a substituição da variedade de algodoeiro, a produtividade do tratamento $t$ se elevou a $1,120 \mathrm{~kg} /$ $110 \mathrm{~m}^{2}$ (Quadro 1). No entanto, uma efetiva melhoria se observou após a terceira calagem, que permitiu a manutenção da produtividade da testemunha em nivel superior a $1,500 \mathrm{~kg} / 10 \mathrm{~m}^{2}$ de algodão em caroço. Coincidentemente, a partir de então, foram obtidos valores de $\mathrm{pH}$ do solo $\left(\mathrm{em} \mathrm{H}_{2} \mathrm{O}\right)$ superiores a 6,0 e diferenças significativas entre as produções médias das parcelas adubadas com misturas contendo superfosfato simples ou triplo, com evidente vantagem para o primeiro produto, conforme figura 1.

Considerando-se os gastos com os adubos fosfatados, com a cobertura nitrogenada diferenciada e com o acréscimo de colheita do algodão devido aos tratamentos, foi possivel avaliar a superioridade, também econômica, do superfosfato simples na mistura de adubos. Embora não se tenha computado o custo do transporte, evidentemente maior para os adubos menos concentrados, observa-se - Figura 2 - que o lucro da cultura, acumulado nos últimos cinco anos, teria aumentado $55 \%$ pela simples troca do superfosfato triplo pelo simples, ao nivel de $50 \mathrm{~kg} / \mathrm{ha}$ de $\mathrm{P}_{2} \mathrm{O}_{5}$; esse índice cresceu para cerca de $82 \%$ na dose dupla de $\mathrm{P}_{2} \mathrm{O}_{5}$. Já a substituição do Nitrocálcio pelo sulfato de amônio na cobertura nitrogenada, em presença da dose máxima dô superfosfato simples, conduziu a um decréscimo de rendimento de $13 \%$. 


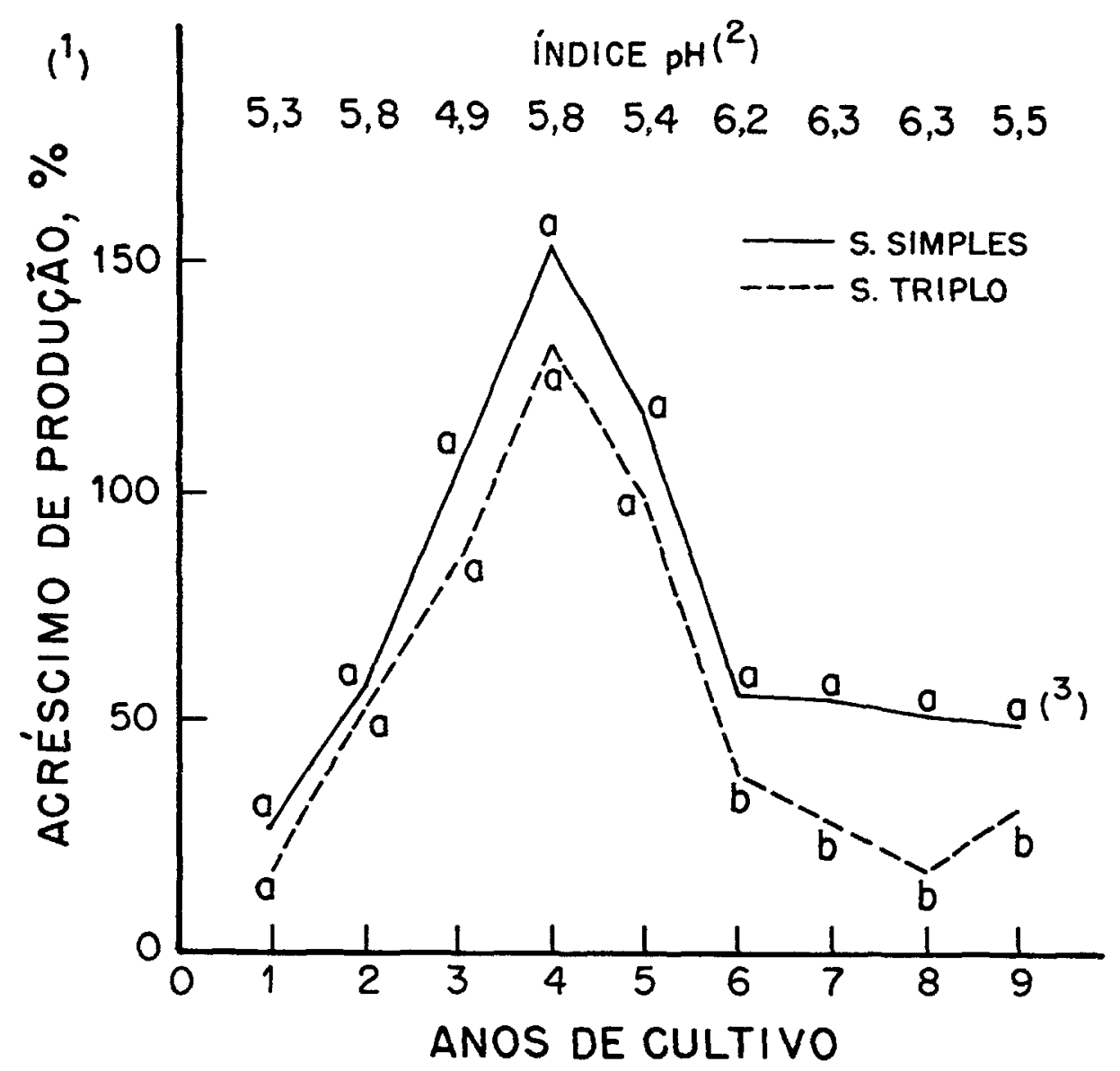

FIGURA 1. Acréscimo porcentual médio de produção, calculado em relação à produtividade da testemunha ( $t$ ), pela aplicação de superfosfato simples ou triplo, em nove anos de ensaio permanente com o algodoeiro sobre latossolo roxo de baixa fertilidade, em Guaira, SP:

(1) Calculado pela relação $100(y 2+y 1) / 2 y 0$, onde y2, y1 e y0 representam, respectivamente, as produções médias dos tratamentos com 100, 50 e zero $\mathrm{kg} / \mathrm{ha}$ de $\mathrm{P}_{2} \mathrm{O}_{5}$.

(2) $\mathrm{pH}$ em $\mathrm{H}_{2} \mathrm{O}$, exceto no último ano, determinado em $\mathrm{CaCl}$.

(3) Teste de Scheffé a 5\% de probabilidade. 


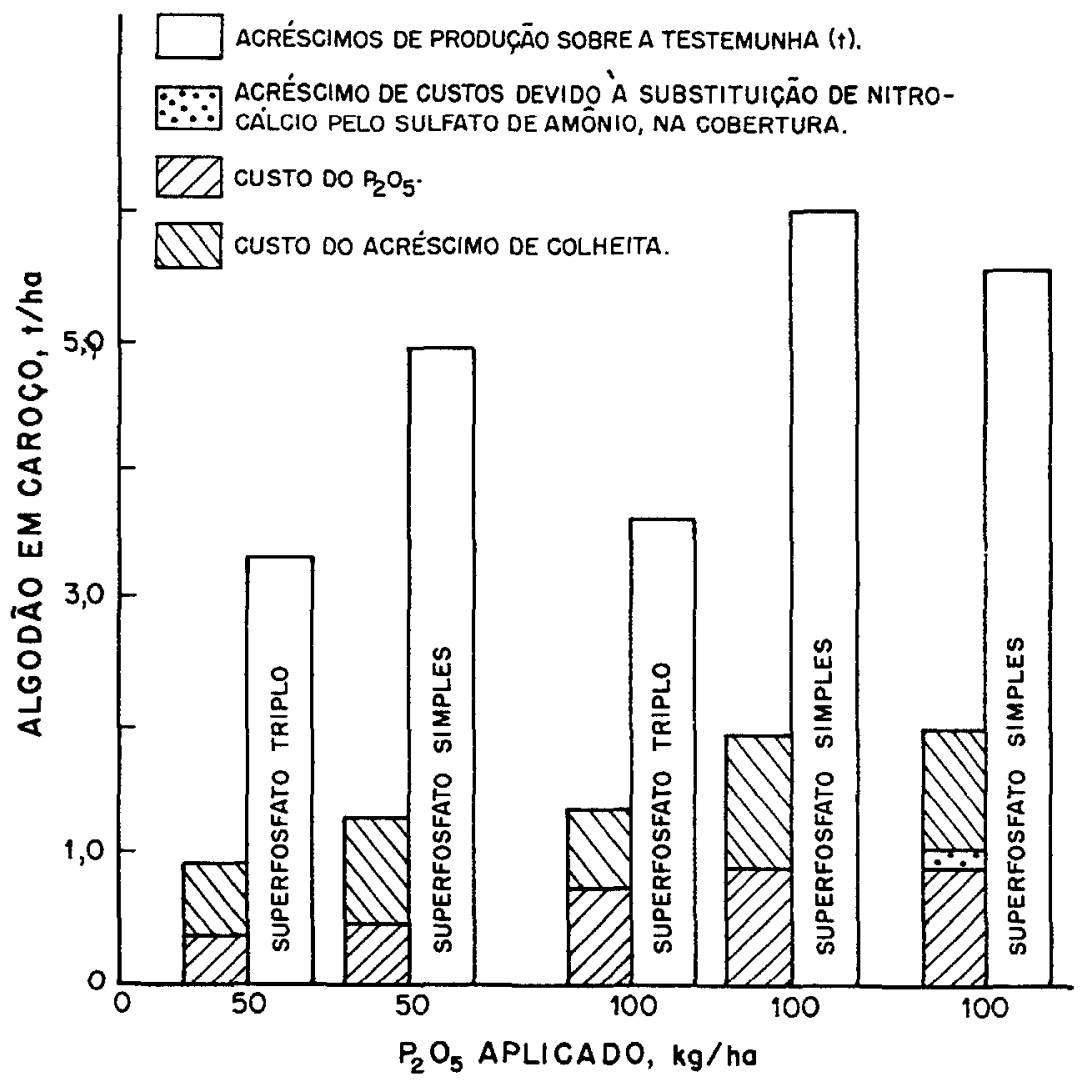

FIGURA 2. Aumentos de produção em relaçāo à testemunha e custos da adubação fosfatada e da cobertura nitrogenada, em termos de produto, acumulados em cinco cultivos sucessivos de algodão.

A partir do quinto ano (1978/79), sintomas de deficiência de enxofre tornaram-se evidentes em parcelas adubadas com superfosfato triplo. Assim, no florescimento, fol has novas das extremidades de ramos carentes, apresentavam-se brilhantes e cloróticas, com aspecto semelhante ao de folhas novas dos citros ("verde-limão"); algumas folhas mais velhas, ao contrário, mostravam-se pálidas, às vezes com o verde normal das nervuras destacando-se do limbo claro (Figura 3a), lembrando, de certa forma, no conjunto, a deficiência de nitrogênio (Figura 3b). As plantas deficientes (Figura 4a) cresciam menos, apresentavam florescimento mais reduzido e maior queda de flores e frutos do que as normais (Figura 4b), além de seca e queda precoces de folhas do "baixeiro". Em linhas gerais, a descrição de tais sintomas coincide com aquela efetuada em outras regiōes produtoras, segundo HINKLE \& BROWN (1968) e PARRY (1982). 

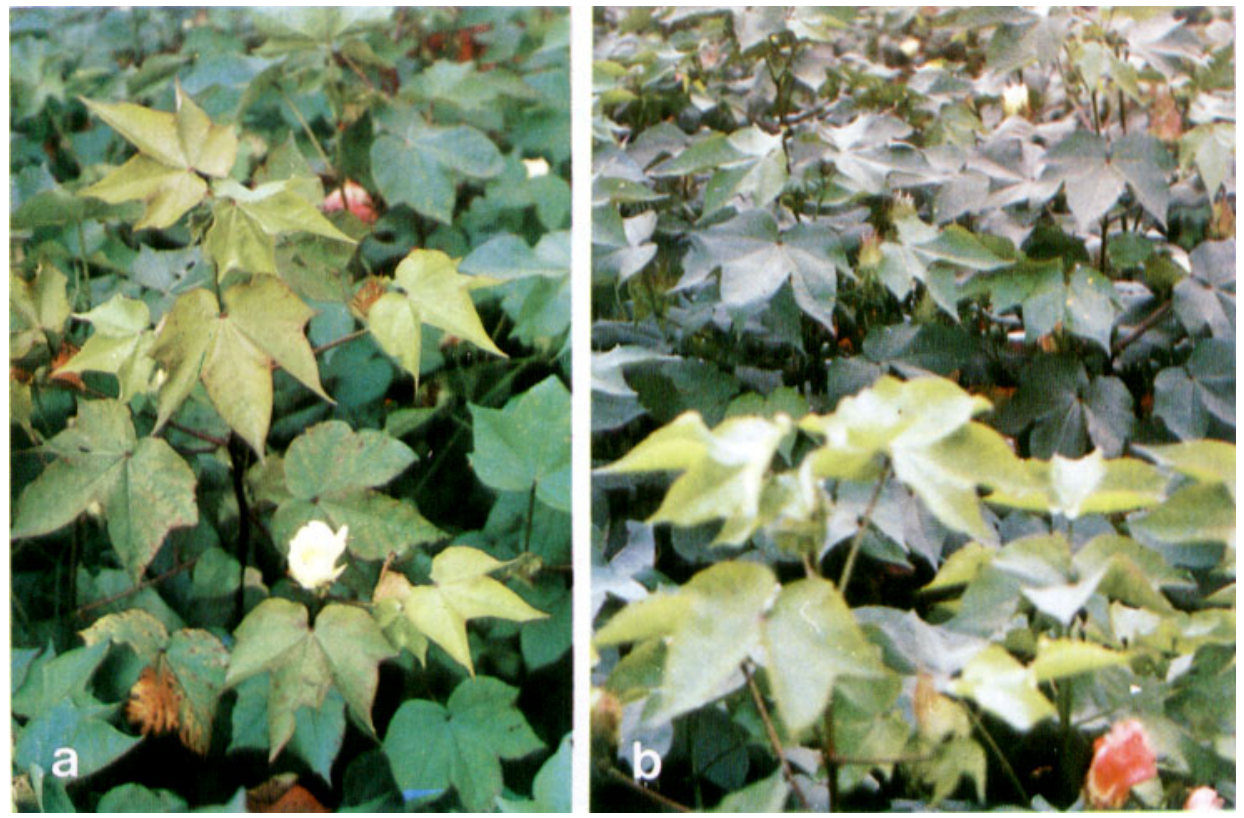

FIGURA 3. a) Sintomas de deficiência de enxofre: folhas novas, das extremidades dos ramos, cloróticas e brithantes ("verde-limão") e folhas mais velhas, pálidas, com certo destaque para o verde normal das nervuras.

b) Contraste entre plantas menores e cloróticas adubadas com superfosfato triplo (frente) e plantas mais vigorosas adubadas com superfosfato simples (fundo).

Os sintomas se repetiram com menor ou maior intensidade nos anos seguintes. Deve-se registrar, também, que no sétimo ano (1980/81), observaram-se prenúncios de deficiência de boro, sob forma de anéis circulares escuros, nos pecíolos foliares de plantas situadas principalmente em parcelas bem adubadas. No último ano de estudo (1982/83), a citada carência foi muito severa, provocando intensa queda de botões florais, flores e frutos novos, especialmente em plantas que receberam a mais alta dose de superfosfato simples, associada $(2 p+4 s)$ ou não $(2 p+2 s)$ a sulfato de amônio.

\subsection{Efeitos sobre características gerais da planta}

No quadro 2, encontram-se os resultados médios de certas características agronômicas da planta e de propriedades tenológicas da fibra algodoeira, obtidos por tratamento, durante o periodo 1978/79-1982/83. 

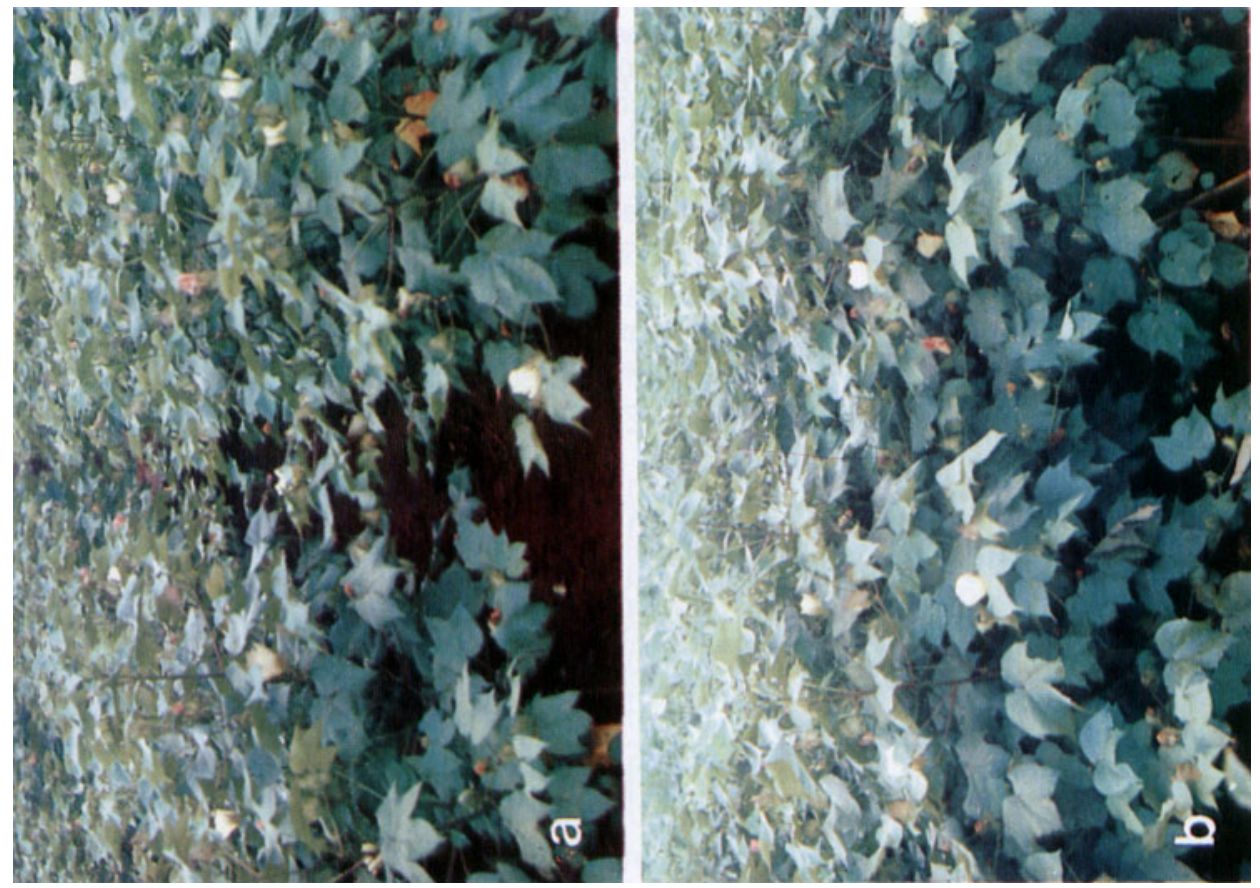

FIGURA 4. Aspecto de parcelas de algodoeiro adubadas durante vários anos com misturas de adubos: $\mathbf{a}=$ sem enxofre $\mathbf{e} \mathbf{b}=$ com enxofre.

Quanto ao caråter precocidade, a proporção da primeira colheita sobre a colheita total cresceu em função da dose de superfosfato triplo acumulada através dos anos. Com efeito, doses de 50 (p) e $100(2 p) \mathrm{kg} / \mathrm{ha}$ de $\mathrm{P}_{2} \mathrm{O}_{5}$ aumentaram 7 e $9 \%$, respectivamente, a precocidade da testemunha sem fósforo (t). Quando se utilizou superfosfato simples, o efeito sobre a precocidade foi bem menor ( 1 a $2 \%)$ e, com a adição de sulfato de amônio em cobertura $(2 p+4 s)$, o algodoeiro se tornou significativamente mais tardio do que aquele adubado com superfosfato triplo mais Nitrocálcio.

O fósforo fornecido pelo superfosfato triplo concorreu para tornar mais pesado o capulho do algodoeiro. Essa melhoria se acentuou com sua troca pelo superfosfato simples. Entretanto, a cobertura com dose suplementar de enxofre $(2 p+4 s)$ praticamente não alterou a média observada para o tratamento referencial $(2 p+2 s)$. No caso do peso de sementes, os efeitos da adubação foram muito semelhantes, embora os indices de aumento tenham sido menores. Já a porcentagem de fibra de algodão caiu com a adubação, de forma antagônica às duas características anteriores. 
QUADRO 2. Resultados médios de propriedades tecnológicas da fibra e de características agronômicas do algodoeiro, obtidos do quinto ao nono ano de condução do ensaio permanente de competição de fosfatos, com a variedade IAC 18, em latossolo roxo de baixa fertilidade, em Gualra, SP, no período 1978/79-1982/83

\begin{tabular}{|c|c|c|c|c|c|c|c|c|c|}
\hline \multicolumn{3}{|c|}{ Tratamento } & \multicolumn{4}{|c|}{ Caracteristicas agronômicas } & \multicolumn{3}{|c|}{ Propriedades tecnológicas } \\
\hline \multirow{2}{*}{ Símbolo } & \multicolumn{2}{|c|}{ Doses } & \multirow{2}{*}{$\begin{array}{l}\text { Preco- } \\
\text { cidade }\end{array}$} & \multirow{2}{*}{$\begin{array}{l}\text { Peso } \\
\text { de um } \\
\text { capulho }\end{array}$} & \multirow{2}{*}{$\begin{array}{c}\text { Peso } \\
\text { de cem } \\
\text { sementes }\end{array}$} & \multirow{2}{*}{$\begin{array}{l}\text { Porcen- } \\
\text { tagem } \\
\text { de fibra }\end{array}$} & \multirow{2}{*}{$\begin{array}{l}\text { Compri- } \\
\text { mento } \\
\text { de fibra }\end{array}$} & \multirow{2}{*}{$\begin{array}{l}\text { Unifor- } \\
\text { midade } \\
\text { de fibra }\end{array}$} & \multirow{2}{*}{$\begin{array}{c}\text { Índice } \\
\text { Micro- } \\
\text { naire }\end{array}$} \\
\hline & $\mathrm{P}_{2} \mathrm{O}_{5}$ & $S$ & & & & & & & \\
\hline & \multicolumn{2}{|c|}{$\mathrm{kg} / \mathrm{ha}$} & $\%$ & g & $g$ & $\%$ & $\mathrm{~mm}$ & $\%$ & \\
\hline$t$ & 0 & 0 & $77,6 a b(1)$ & $6,34 \mathrm{c}$ & $12,08 \mathrm{c}$ & $41,56 \mathrm{a}$ & $26,75 d$ & 46,88 & $5,91 \mathrm{a}$ \\
\hline p & 50 & 0 & $82,8 a$ & $6,56 b$ & $12,14 \mathrm{C}$ & $40,61 b$ & $26,90 \mathrm{~cd}$ & 46,99 & $4,72 b$ \\
\hline 2p & 100 & 0 & $84,9 a$ & $6,64 b$ & $12,49 a b$ & $40,42 \mathrm{bc}$ & $27,07 \mathrm{bc}$ & 46,75 & $4,68 b$ \\
\hline $\mathbf{p}+\mathbf{s}$ & 50 & 30 & $79,2 a b$ & $6,70 a b$ & $12,35 \mathrm{bc}$ & $40,37 \mathrm{bc}$ & $27,05 \mathrm{c}$ & 47,24 & $4,72 b$ \\
\hline $2 p+2 s$ & 100 & 60 & $78,6 a b$ & $6,83 a$ & $12,71 a$ & $39,78 d$ & $27,38 a$ & 47,34 & $4,71 b$ \\
\hline $2 p+4 s$ & 100 & 120 & $71,7 \mathrm{~b}$ & $6,86 a$ & $12,71 \mathrm{a}$ & $39,91 \mathrm{~cd}$ & $27,33 a b$ & 47,09 & $4,64 b$ \\
\hline \multirow{3}{*}{\multicolumn{3}{|c|}{$\begin{array}{l}\text { Média } \\
\text { "F" - Trato } \\
\text { CV\% }\end{array}$}} & 79,1 & 6,66 & 12,41 & 40,44 & 27,08 & 47,05 & 4,73 \\
\hline & & & $3,40^{\star}$ & $9,51^{\star *}$ & $7,29^{\star *}$ & $10,90^{\star \star}$ & $6,50^{* *}$ & 1,94 & $5,79^{* *}$ \\
\hline & & & 6,8 & 3,7 & 3,0 & 1,8 & 1,9 & 1,9 & 4,7 \\
\hline
\end{tabular}

(1) Teste de Duncan a 5\% de probabilidade. Comparação entre médias de tratamentos, para cada caracteristica.

A semelhança do que ocorreu com o peso de capulho, o comprimento e a uniformidade da fibra algodoeira reagiram mais à aplicação do superfosfato simples do que do triplo, não sendo afetados por adubação suplementar com sulfato de amônio $(2 p+4 s)$. Quanto ao índice Micronaire, houve um decréscimo em seu valor médio, em função do uso geral de adubo.

\section{DISCUSSÃO E CONCLUSÕES}

A tendência para crescente efeito da adubação fosfatada observada atravĕs dos años, na primeira fase do estudo - segundo dadós de SILVA et al. (1981), resumidos na primeira parte da figura 1 - reflete o deficiente aproveitamento do fósforo pelo algodoeiro com condições de acidez, confirmando resultados de RAMOS et al. (1960) e SILVA et al. (1981). Aliás, nessa fase inicial, só foram alcançados niveis razoáveis de produtividade quando se aplicaram fósforo e enxofre juntos na adubação. Entretanto, até o quarto ano, nāo foi detectado o clássico sintoma de carência de enxofre, conhecido como clorose "verde-limão" das folhas novas (MENDES, 1966). 
Com o sensivel aumento médio da produtividade a partir do quinto ano, devido ao cultivo da mucuna em rotação (SILVA, 1984) e à troca da variedade de algodoeiro (GRIDI-PAPP et al., 1985), registraram-se os primeiros sintomas de deficiência de enxofre em parcelas adubadas com superfosfato triplo. Somente, porém, após a terceira calagem - que concorreu para estabilizar o $\mathrm{pH}\left(\mathrm{em} \mathrm{H}_{2} \mathrm{O}\right)$ do solo, ao redor de 6,2, e a produtividade das plantas acima de $1,500 \mathrm{~kg} / 10 \mathrm{~m}^{2}$ é que as diferenças a favor das misturas contendo superfosfato simples se tornaram significativas. McCLUNG et al. (1961), trabalhando na mesma região, demonstraram que a aplicação de enxofre no algodoeiro cultivado após correção da acidez dos solos para $\mathrm{pH} 6,0$, so foi superada em importância pela prática da calagem.

A baixa reserva mineral de enxofre nesse tipo de solo, (MCCLUNG et al., 1961) e a contínua exportação do nutriente através das colheitas (MALAVOLTA, 1985), principalmente nos últimos anos, de alta produtividade, poderiam explicar o surgimento da deficiência de enxofre e o crescimento do efeito do uso de superfosfato simples na adubaçāo. Entretanto, há que se lembrar a possibilidade de perda por lixiviação de ions sulfatos, tendo em vista prováveis incentivos na decomposição da matéria orgânica e queda na intensidade de adsorção do ânion pelos colóides minerais, com a calagem (WUTKE, 1972).

Embora a deficiência de enxofre tenha ocorrido freqüentemente a partir do quinto ano de cultivo, em parcelas testemunhas, a sua aplicação suplementar, sob a forma de sulfato de amônio em cobertura, mostrou-se desnecessária e mesmo inconveniente em alguns casos, nesse segundo periodo. Pode-se inferir, portanto, que a dose adequada de enxofre, após a devida correção da acidez do solo, nāo deve ultrapassar $60 \mathrm{~kg} / \mathrm{ha}$ de S. Registre-se, todavia, que em condiçōes mais severas de acidez, como ocorreu nos primeiros anos desse estudo (SILVA et al., 1981), o algodoeiro reagiu mais favoravelmente à aplicação suplementar do referido nutriente.

O superfosfato simples na adubação do algodoeiro, além de ter suplantado o triplo em termos de produtividade e de lucro, proporcionou a formação de capulhos maiores com sementes mais pesadas, à semelhança do que ocorreu na fase inicial desse estudo (SILVA et al., 1981). Essa superioridade se estendeu, na segunda fase, a caracteristicas de fibra, tendo o superfosfato simples aumentado significativamente seu comprimento e concorrido, de certa forma, para diminuir o número de fibras curtas, ou seja, melhorar a uniformidade de comprimento. Por todos esses fatos, seria conveniente repensar nas rotas de solubilização de rochas fosfáticas, visando à produção de adubos.

Por sua vez, a porcentagem de fibra, de forma antagônica ao peso de sementes, caiu com a adubação fosfatada e, mais ainda, corn a adição de enxofre. Tendo em vista, no entanto, os destacados aumentos de produção de algodão em caroço devidos à aplicação desses nutrientes, também cresceu a quantidade de fibra produzida por área. Da mesma forma, o indice Micronaire diminuiu com a 
aplicação geral de adubos, porém, na prática, tais transformações não chegam a representar perdas de qualidade, desde que os menores valores obtidos, 39,78 para porcentagem de fibra e 4,64 para indice Micronaire, se enquadram nas variaçōes observadas em experimentação regional recente, respectivamente 39,79 a $39,89 \%$ e 4,63 a 5,14 (GRIDI-PAPP et al., 1985).

Do exposto, podem-se extrair as seguintes conclusões:

1) A necessidade de enxofre na adubação do algodoeiro tornou-se evidente após um sensivel e gradativo aumento de produtividade das plantas, obtido em ensaio de longa duração com a substituição de variedade, o cultivo de leguminosa em rotação e a correção adequada da acidez de um latossolo roxo de baixa fertilidade.

2) Sintomas de deficiência de enxofre nas parcelas testemunhas tornaram-se evidentes somente a partir do quinto ano de plantio sucessivo de algodão.

3) Misturas contendo superfosfato simples, nos últimos cinco anos, superaram estatisticamente misturas com superfosfato triplo, em termos de produção, aumento do lucro, peso de capulho e comprimento de fibra; admitindo-se que essa superioridade se deva, pelo menos em parte, à presença do enxofre, há que se reavaliar a necessidade de incorporação desse nutriente nas formulações comerciais de adubos.

4) A dose suplementar de enxofre (superior a $60 \mathrm{~kg} / \mathrm{ha}$ de $S$, no entanto, não modificou, de modo geral, as características.

5) Enquanto o fósforo concorreu para aumentar significativamente a proporção da primeira colheita de algodão, misturas contendo fósforo mais enxofre conduziram a ciclo de colheita mais longo.

6) Embora a porcentagem de fibra tenha caído com o uso de fósforo e de enxofre, o total de fibra por área aumentou, em conseqüência do destacado efeito da adubação sobre a produção de algodão em caroço.

7) Ocorreu queda no indice Micronaire pelo uso de adubos, destituída de importância prática, tendo em vista os adequados niveis geralmente obtidos para a característica.

\section{SUMMARY}

\section{PHOSPHATE FERTILIZERS COMPETITION IN A LONG TERM} EXPERIMENT WITH COTTON, ON A DUSKY RED LATOSOL

After four years of consecutive applications of fertilizer mixtures containing $P$ with or without $S$, in a long term trial conducted with cotton, on an acid and low-fertility Dusky Red Latosol, velvet bean (Stizolobium atterrimum Piper \& Tracy) was cultivated and limestone enough to attain the soil $\mathrm{pH}$ around 6.2, was applied. During the next five years, from 1978 to 1983, 
IAC 18 cotton cultivar was grown with the same fertilization of the initial phase of study. $\mathrm{N}$ and $\mathrm{K}$ were supplied in constant dosis, and $\mathrm{P}$ and $\mathrm{S}$ in variable dosis, through the combination of ammonium sulfate, nitrochalk, ordinary superphosphate, triple superphosphate and potassium chloride. Sulfur deficiency symptoms such as the appearance of yellow leaves at the top of plants ("lemon green") occurred from fifth year on, in the plots which received no $S$, in accordance with a tendency of increasing yieid. However, only after acidity correction, it was possible to maintain high cotton yield and to obtain differences statistically significant between fertilizer mixtures with or without $S$. In the last five-year period, annual application of 50 and $100 \mathrm{~kg} / \mathrm{ha}$ of $\mathrm{P}_{2} \mathrm{O}_{5}$ increased cotton yield, respectivelly of 37 and $40 \%$, as triple superphosphate and of 55 to $67 \%$, in the case of ordinary superphosphate. With regard to economical aspects, boll weight and fiber lenght, ordinary superphosphate was also superior. The use of additional doses of $S(120 \mathrm{~kg} / \mathrm{ha})$ however, did not improve the performance of cotton fertilized with $60 \mathrm{~kg} / \mathrm{ha}$ of $S$. It was proposed that $S$ should be incorporated in commercial fertilizer mixtures.

Index terms: cotton, boll weight, fiber lenght, ordinary and tiple superphosphate.

\section{REFERÊNCIAS BIBLIOGRÁFICAS}

GRIDI-PAPP, I.L.; FUZATTO, M.G.; CIA, E.; CHIAVEGATO, E.J.; SABINO, N.P.; KONDO, J.I.; SILVA, N.M. da; CARVALHO, L.H.; MARTINS, A.L.M.; PETTINELLI JÜNIOR, A.; SORDI, G. de; SABINO, J.C.; PEREIRA, J.C.V.N.A.; CAMPANA, M.P.;BORTOLETTO, N. \& GALLO, P.B. Ensaios regionais de variedades paulistas de algodoeiro. VI. 1977/78-1978/79. Campinas, Instituto Agronómico, 1985. 89p. (Boletim Cientffico, 4)

HINKLE, D.A. \& BROWN, A.L. Secondary nutrients and micronutrients. In: ADVANCES in production and utilization of quality cotton-principles and practices. Ames, lowa Sta. Univ. Press, 1968. p.280-366.

MCCLUNG, A.C.; FREITAS, L.M.M.; MIKKELSEN, D.S. \& LOTT, W.L. A adubação do algodoeiro em solos de campo cerrado no Estado de São Paulo. São Paulo, IBEC Research Institute, 1961. 35p. (Boletim, 27)

MALAVOLTA, E. \& KLIEMANN, H.J. Desordens nutricionais no cerrado. Piracicaba, Potatos, 1985. 136p.

MENDES, H.C. Nutriçăo mineral. In: CULTURA e adubação do algodoeiro. São Paulo, Instituto Brasileiro de Potassa, 1966. p.461-473.

MENGEL, K. \& KIRKBY, E.A. Sulfur. In: PRINCIPLES of plant nutrition. Bern, International Potash institute, 1978. p.229-346.

PARRY, G. Le cotonnier et ses produits. Paris, G.-P.Maisonneuve \& Larose, 1982. 502p. 
RAMOS, I.; SCHMIDT, W.; CAVALERI, P.A. \& NEVES, O.S. Adubação do algodoeiro. IX. Ensaios com diversos adubos fosfatados ( $3^{\mathrm{a}}$ série). Bragantia, Campinas, 19(1):101$127,1960$.

SILVA, N.M. Efeitos da rotaçăo de culturas em algodão, no Estado de São Paulo. In: ADUBAÇÃO verde no Brasil.. Campinas, Fundação Cargill, 1984. p.124-128.

; RODRIGUES FILHO, F.S.O. \& HIROCE, R. Uso de misturas de adubos contendo ou não enxofre na adubação do cultivar IAC 16 de algodoeiro. Bragantia, Campinas, 40:167-178, 1981.

WUTKE, A.C.P. Acidez. In: ELEMENTOS de Pedologia. Sāo Paulo, Polfgono, Ed. da Univ. de São Paulo, 1972. p.149-168. 